\title{
HRCT EVOLUTION IN COVID 19 PATIENT
}

\author{
MD ROBED AMIN ${ }^{1}$, MD KHALILUR RAHMAN ${ }^{2}$
}

\section{Introduction:}

COVID-19 although is a maultisystem disease, the major impact still remain in the lungs. There are variable findings presented in both lungs which can

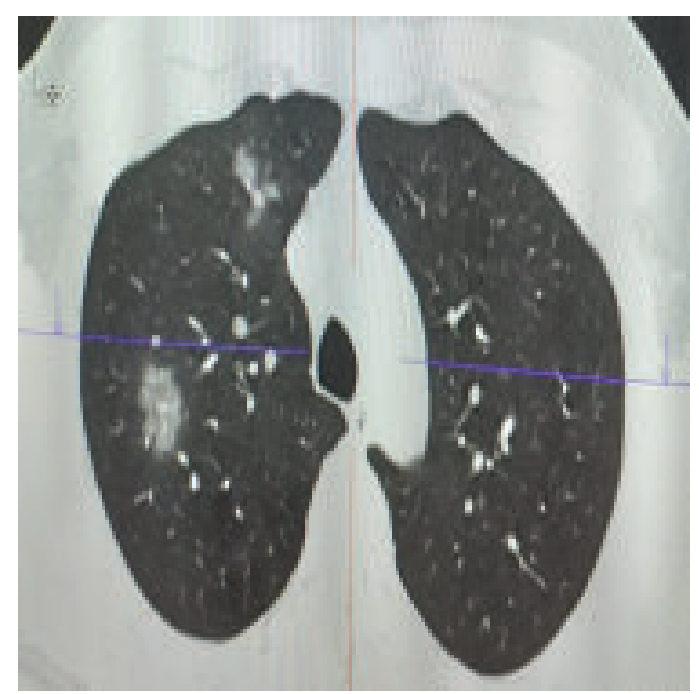

be observed in time bound findings in HRCT of chest. A middle age RTPCR positive for SARSCoV-2 was investigated with the sensitive HRCT on $6^{\text {th }}$ day of illness with subsequent folow up on $9^{\text {th }}$ day.

Fig 1 a\&bb: GGO in axial section initially visible on right side and later bilateral peripheral in all territory
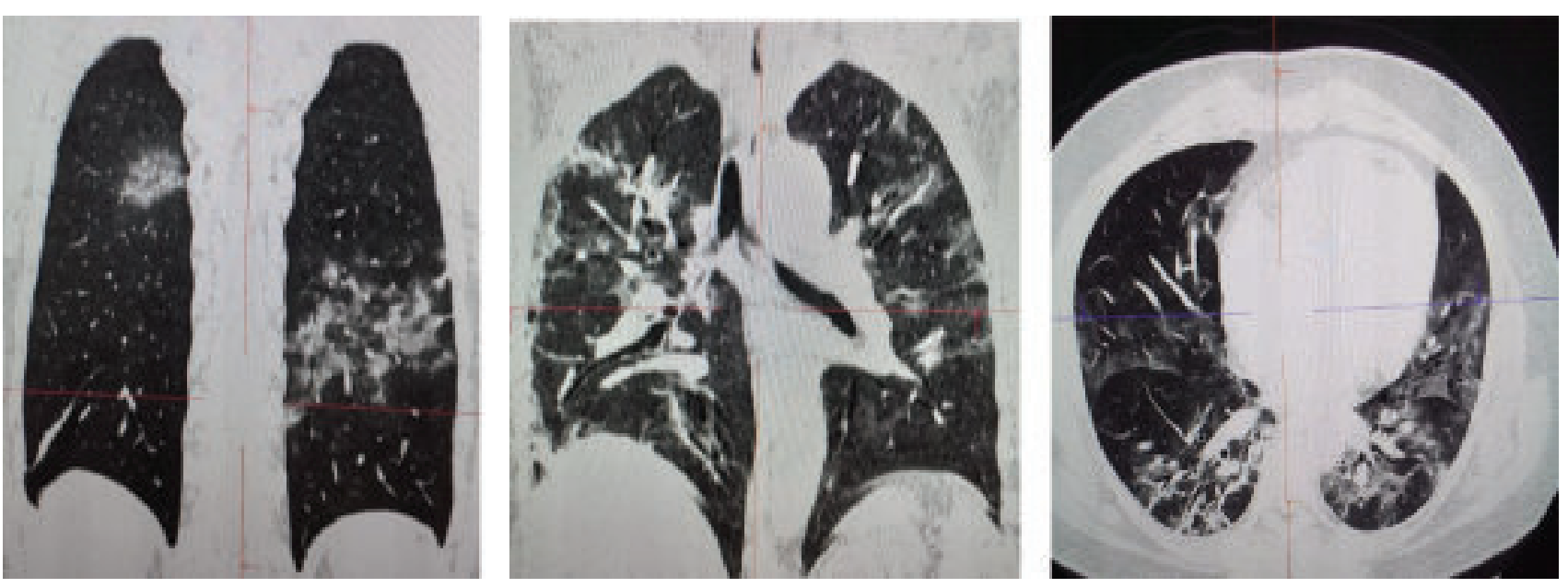

Fig 2 (c, d and e) : GGO, Air Bronchogram, septal thickening, vessel prominence,crazy paving,fibrotic septa

1. Professor of Medicine, Dhaka Medical College

2. Professor of Radiology, Sheikh Hasina Burn Institute,Dhaka

Address of Correspondence: Dr. Md Robed Amin, Professor of Medicine, Dhaka Medical College 
Chest axial HRCT image (a) showing multiple foci of Ground glass opacity (GGOs) distributed peripherally involving posterior and lateral segments right lower lobe, lateral segment of left lower lobe and lateral segment of right middle lobe ${ }^{1}$. Reconstructed axial image shows bilateral distribution of GGOs(b). More widespread and multifocal areas of GGO involving all the visible lobes of both lungs in diffuse but predominantly peripheral and posterior distribution, seen in coronal HRCT images ( $c \& d$ ) and in reformatted coronal image(e). Small areas of soft tissue densities with air bronchogram are observed. Thickened vessels are also seen, crazy paving and fibrotic band is also observed when the patient develop ARDS ${ }^{2}$

HRCT scan of chest is the earliest sensitive test for diagnosing COVID-19 and the sensitivity even better than RTPCR test ${ }^{3}$. The earlier findings are GGO, although not specific, but significant if associated with respiratory symptom and also with microthrombi formation in pulmonary vessels. ${ }^{4}$ Although commonly bilateral, there may be unilateral finding and sequential involvement also observed. ${ }^{3 .}$ Subsequent findings are crazy paving pattern, vessel prominence, air bronchogram all are consistent with viral pneumonia ${ }^{2.3,4}$. The later on fibrotic band also seen in few patients who develop ARDS

\section{Reerences:}

1. Lei J, Li J, Li X, Qi X. CT imaging of the 2019 novel coronavirus (2019-nCoV) pneumonia. Radiology 2020 Jan 31 https://doi.org/10.1148/radiol.2020200236 PMid:32003646 PMCid:PMC7194019

2. Cheng Z, Lu Y, Cao Q, et al. Clinical features and chest CT manifestations of coronavirus disease 2019 (COVID19) in a single-center study in Shanghai, China. AJR 2020 Mar 14 https://doi.org/10.2214/AJR.20.22959 PMid:32174128

1. Wang H, Wei R, Rao G, Zhu J, Song B. Characteristic CT findings distinguishing 2019 novel coronavirus disease (COVID-19) from influenza pneumonia. European Radiology. 2020 Apr. DOI: 10.1007/s00330020-06880

2. Bernheim A, Mei X, Huang M, Yang Y, Fayad ZA, Zhang N, Diao K, Lin B, Zhu X, Li K, Li S. Chest CT findings in coronavirus disease-19 (COVID-19): relationship to duration of infection. Radiology. 2020 Feb 20:200463. https:// doi.org/10.1148/radiol.2020200463 PMid:32077789 PMCid:PMC7233369 